\title{
Autologous esophageal mucosa with polyglycolic acid transplantation and temporary stent implantation can prevent stenosis after circumferential endoscopic submucosal dissection
}

\author{
Yong Liü, Zhengqi Li" ${ }^{\#}$, Lizhou Dou\#, Yueming Zhang, Shun He, Jiqing Zhu, Yan Ke, Xudong Liu, \\ Yumeng Liu, Hoiloi Ng, Guiqi Wang^ \\ Department of Endoscopy, National Cancer Center/National Clinical Research Center for Cancer/Cancer Hospital, Chinese Academy of Medical \\ Sciences and Peking Union Medical College, Beijing, China \\ Contributions: (I) Conception and design: G Wang, Y Liu, Z Li, L Dou; (II) Administrative support: G Wang; (III) Provision of study materials or \\ patients: Y Zhang, S He; (IV) Collection and assembly of data: J Zhu, Y Ke, X Liu, H Ng; (V) Data analysis and interpretation: Y Liu, Z Li; (VI) \\ Manuscript writing: All authors; (VII) Final approval of manuscript: All authors. \\ \#These authors contributed equally to this work. \\ Correspondence to: Guiqi Wang. Department of Endoscopy, National Cancer Center/National Clinical Research Center for Cancer/Cancer Hospital, \\ Chinese Academy of Medical Sciences and Peking Union Medical College, Beijing 100021, China. Email: wangguiq@126.com.
}

Background: This research aimed at investigating the safety and efficacy of autologous esophageal mucosa (AEM) with polyglycolic acid (PGA) transplantation and temporary stent implantation (TSI) in preventing esophageal stenosis (ES) after early esophageal cancer (EC) surgery.

Methods: Between April 2019 and October 2020, patients scheduled for circumferential endoscopic submucosal dissection (ESD) were prospectively recruited. After ESD, autologous esophageal mucosal patches (MPs) were constructed on the absorbable PGA felt. Then, the felt was structured onto a covered metal mesh stent (CMMS) and attached to the ulcer surface. The stents were removed 6-8 weeks after the operation. The occurrence of ES and adverse events was observed and analyzed.

Results: Data from 25 patients were analyzed. In total, 14 patients $(56 \%)$ had no stenosis during an average follow-up of 10.2 months, and 11 patients (44\%) suffered strictures at a mean interval of 63.73 days after the ESD procedure. Stent migration occurred in 2 patients. No other complications, including perforations, bleeding, or wound infections, occurred. The median of endoscopic balloon dilatation (EBD) sessions was 2.16 (range, 0-14). There showed a higher post-ESD stricture rate in patients with lesions located in the middle-lower esophagus $(\mathrm{P}<0.05)$. More transplanted MPs may reduce the occurrence of ES.

Conclusions: AEM with PGA transplantation and TSI is a safe and effective approach of preventing ES and improving the life quality after circumferential ESD.

Keywords: Autologous esophageal mucosa (AEM); polyglycolic acid (PGA); temporary stent implantation (TSI); circumferential endoscopic submucosal dissection (ESD); stenosis

Submitted Oct 19, 2020. Accepted for publication Jan 17, 2021.

doi: $10.21037 /$ atm-20-6987

View this article at: http://dx.doi.org/10.21037/atm-20-6987

^ ORCID: Zhengqi Li, 0000-0002-1351-8410; Guiqi Wang, 0000-0003-3226-9285. 


\section{Introduction}

Endoscopic submucosal dissection (ESD) sets a standard for precancerous lesions, and early esophageal cancers (ECs) confined to the submucosa with a low risk of distant metastases $(1,2)$.

Nevertheless, notably, the incidence of stenosis after circumferential early EC resection is very high (75\% to 100\%) $(3,4)$, resulting in dysphagia, an impaired quality of life and a substantial increase in financial burden. As there are still no effective treatment methods for stenosis, some interventions are considered to be effective in preventing post ESD stenosis, including repeated endoscopic balloon dilation (EBD), oral steroids, viscous budesonide slurry, and local injection of steroids (1,5-8). Recently, several studies suggested that temporary stent placement (9), polyglycolic acid (PGA) (10), oral mucosal sheets (11), autologous skin grafting (12) and autologous esophageal mucosa (AEM) (13) may contribute to prophylactically preventing stenosis in patients with circumferential mucosal defects after ESD. However, these methods all have limitations.

For preventing esophageal stricture, we developed AEM with PGA transplantation and temporary stent implantation (TSI) (14). We designed this method based on the following considerations. First, PGA has been proved as a potential approach for reinforcing sutures and minimizing scar contracture in other medical areas. Second, AEM may play a role as punctate skin grafting in orthopedic surgery. Third, stents can support ulcers such that stenosis can be prevented. We present the following article in accordance with the STROBE reporting checklist (available at http://dx.doi.org/10.21037/atm20-6987).

\section{Methods}

\section{Patients}

The study was conducted in accordance with the Declaration of Helsinki (as revised in 2013). This phase I pilot investigation was ratified by the Ethics Committee of the National Cancer Center/Cancer Hospital, Chinese Medical College and Peking Union Medical College (No. 19/1911975), and all patients had signed written informed consents. The phase I pilot investigation was carried out from April 2019 to October 2020 in National Cancer Center/Cancer Hospital, Chinese Medical College and Peking Union Medical College.

The inclusion criteria were below: (I) patients with wholly circumferential esophageal squamous-cell carcinoma and no invasion exceeding SM1 by biopsy; (II) patients who underwent ESD; and (III) no lymph node metastases by computed tomography (CT).

The exclusion criteria were below: (I) patients with esophageal stenosis (ES) at baseline; (II) patients with coagulopathy or continuous use of anticoagulant and antiplatelet drugs; and (III) lymph node metastases by CT.

\section{Sample size}

Because this study was a phase I pilot study, we did not calculate the required sample size.

\section{ESD procedure}

Circumferential early EC was resected by ESD as described in a previous publication (13).

\section{AEM with PGA transplantation and TSI}

After ESD, several pieces of autologous esophageal mucosal tissue from these patients were excised by multiband mucosectomy (MBM) adopting a Duette kit (HX-20Q-1; Olympus, Tokyo, Japan) from a normal esophagus site $1 \mathrm{~cm}$ away from the lesion. Then, MBM was sliced into 3 to $8 \mathrm{~mm}$ mucosal patches (MPs). Subsequently, absorbable lines (VCP738D; Johnson \& Johnson, New Brunswick, America) were used to reconstruct these pieces on the absorbable PGA felt (Neoveil, $100 \times 50 \times 0.15 \mathrm{~mm}$; Gunze Co., Tokyo, Japan). Notably, the mucosal side was connected to the PGA felt so the submucosal side would be in contact with the ESD ulcer in each MP. The vertical and horizontal distance between each of two MPs was $1.0 \mathrm{~cm}$. We measured the length of ulcer endoscopically after the resection and the suitable length of stent was chosen. Then, the felt was made onto a covered metal mesh stent (CMMS) (MTNSE-S-20/160-A-8/650, MTN-SE-S-20/100-A-8/650, MTN-SE-S-18/120-A-8/650; Nanjing Micro Technology Co, Ltd., China). The endoscope was passed through the stent with grasping forceps through the biopsy channel to grasp the distal steel lasso loop of the stent. Eventually, the stent was positioned on the surface of the ulcer. Before stenting, a tube was placed through the mouth (MD-48618, Sumitomo bakelite Co., Ltd., Tokyo, Japan) to facilitate stent passage and protect digestive mucosa from injury. After the procedure was finished, a gastric tube was placed 

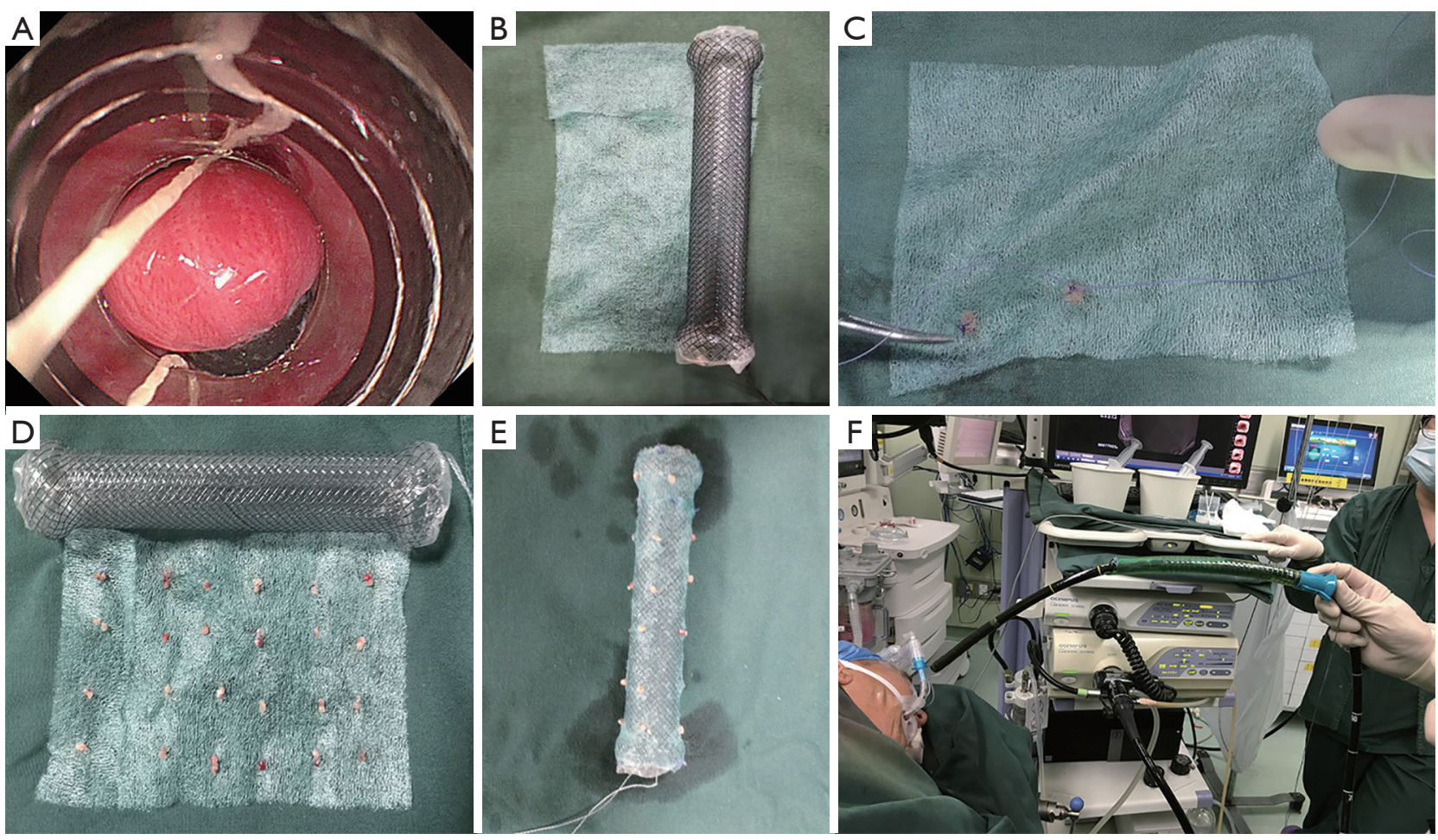

Figure 1 Autologous esophageal mucosa (AEM) with polyglycolic acid (PGA) transplantation and temporary stent implantation (TSI) surgery. (A) MBM was used to remove the AEM. (B) A suitable stent and PGA sheet were chosen. (C,D) The esophageal mucosa was sutured on PGA. (E) The PGA sheet was sutured on a completely covered esophageal stent. (F) Under direct endoscopy, the stent was placed in the esophageal defect by releasing the steel sheath grommet.

under endoscopy.

\section{Aftercare}

The patients were asked to continue fasting for the first three days after ESD and then underwent CT on the third day to determine whether there were perforations or stent migrations. On the $4^{\text {th }}$ day after the operation, the patients were allowed to start a liquid diet, and on the $7^{\text {th }}$ day, the gastric tube was removed. After ESD, the patient received a proton pump inhibitor (rabeprazole $20 \mathrm{mg}$; Changao, Nanjing, China) for 6 consecutive days. After that antibiotics were given 3 days $\mathrm{q} 12 \mathrm{~h}$ (Amoxicillin sodium sulbactam sodium $1.25 \mathrm{~g}$; Ruiyang, Shandong, China).

\section{Stent removal}

A scheduled endoscope examination was performed once a week to confirm the position of the stent, which was removed during the $6^{\text {th }}-8^{\text {th }}$ week after the operation depending on the patient's tolerance (Figures 1,2).

\section{Stricture and follow-up}

Patients were examined by endoscopy 2 weeks and 3 and 6 months after the stent removal and then annually. When the standard endoscope (GIF-H290; Olympus, Tokyo, Japan) cannot pass through the stenosis, it is defined as ES. EBD treatment was used in patients with postoperative stricture. If the patient had stenosis symptoms, they can connect our doctors and the EBD will also be done. During the EBD treatment, a special balloon (Wilson-Cook Medical Incorporated, Bloomington, Indiana, USA) $1.2-1.5 \mathrm{~cm}$ in size was selected on basis of the degree of ES. The duration of EBD varied among the patients with the aim to relieve dysphagia.

\section{Statistical analysis}

The statistical comparison was performed by $t$-test and 

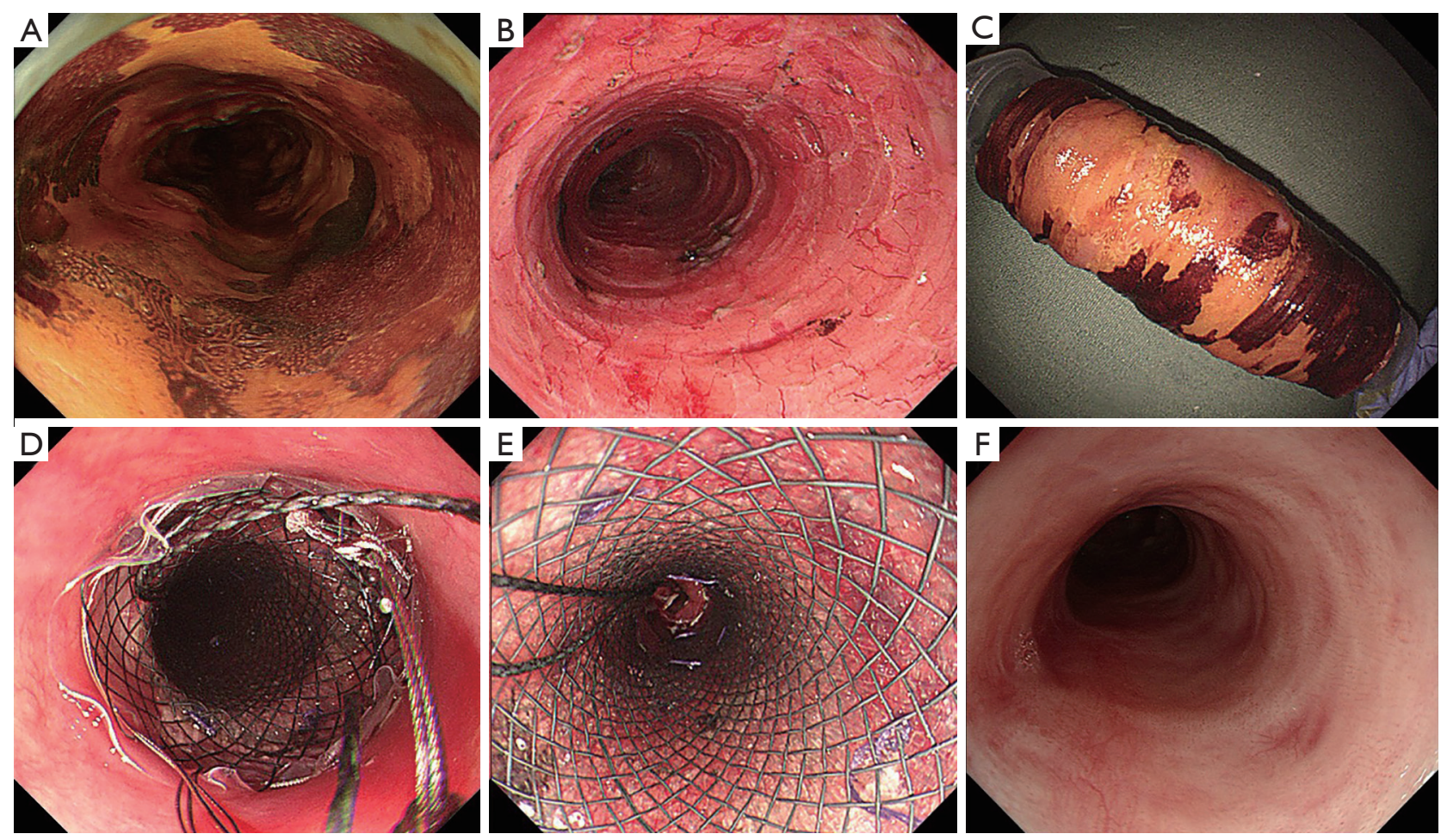

Figure 2 One case of prevention of ES was conducted with PGA AEM transplantation and TSI. (A) Lugol iodine staining showed a complete annular lesion in the esophageal lumen. (B,C) ESD caused a wholly circumferential mucosal defect. (D) The stent was placed at the site of the artificial esophageal ulcer. (E) The patient underwent a weekly endoscopy to confirm that the stent was in place. (F) No evidence of stenosis was observed 6 months after transplantation.

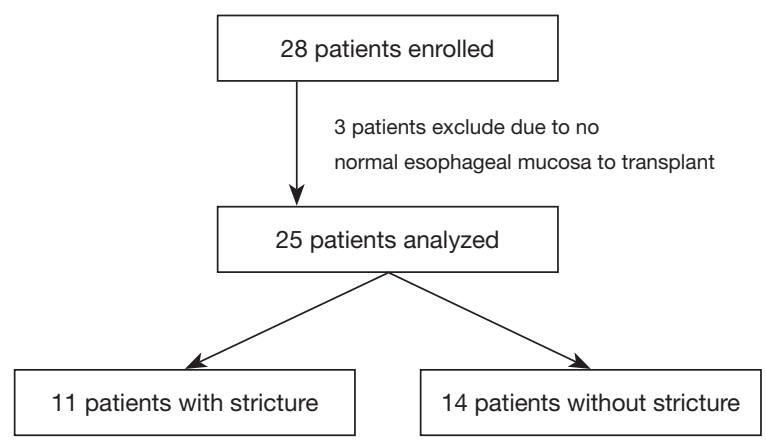

Figure 3 Flow chart of the patients included in this investigation. Of the 28 patients enrolled, twenty-five patients with ESD, followed by AEM with PGA transplantation and TSI, were evaluated endoscopically and analyzed.

the Mann-Whitney $\mathrm{U}$ test to analyze the parametric and nonparametric data, separately, with significance assumed at $\mathrm{P}$ values $<0.05$. The statistical calculations were conducted employing SPSS25 software (SPSS Inc., Chicago, IL, USA).

\section{Results}

\section{Enrollment and procedures}

A total of 28 patients were included in this research. However, after ESD, 3 patients did not have any normal mucosa remaining to transplant. Therefore, 25 patients underwent the complete study protocol and were included in the analysis (Figure 3, Table 1). The biopsies confirmed the esophagus squamous epithelium at the transplant site according to the histological features of a normal esophagus.

\section{Overall outcomes}

All 25 patients successfully underwent a combination of circumferential ESD, AEM with PGA transplantation and TSI. Stent removal was conducted in 2 patients with complaints of thoracalgia during the $3^{\text {rd }}$ and $4^{\text {th }}$ weeks after ESD. In our study, we found that the PGA sheet and absorbable line can be absorbed totally in 6 weeks. Even in the cases we have to remove the stents in 3 or 4 weeks, the 
Table 1 Demographic features of patients and lesions

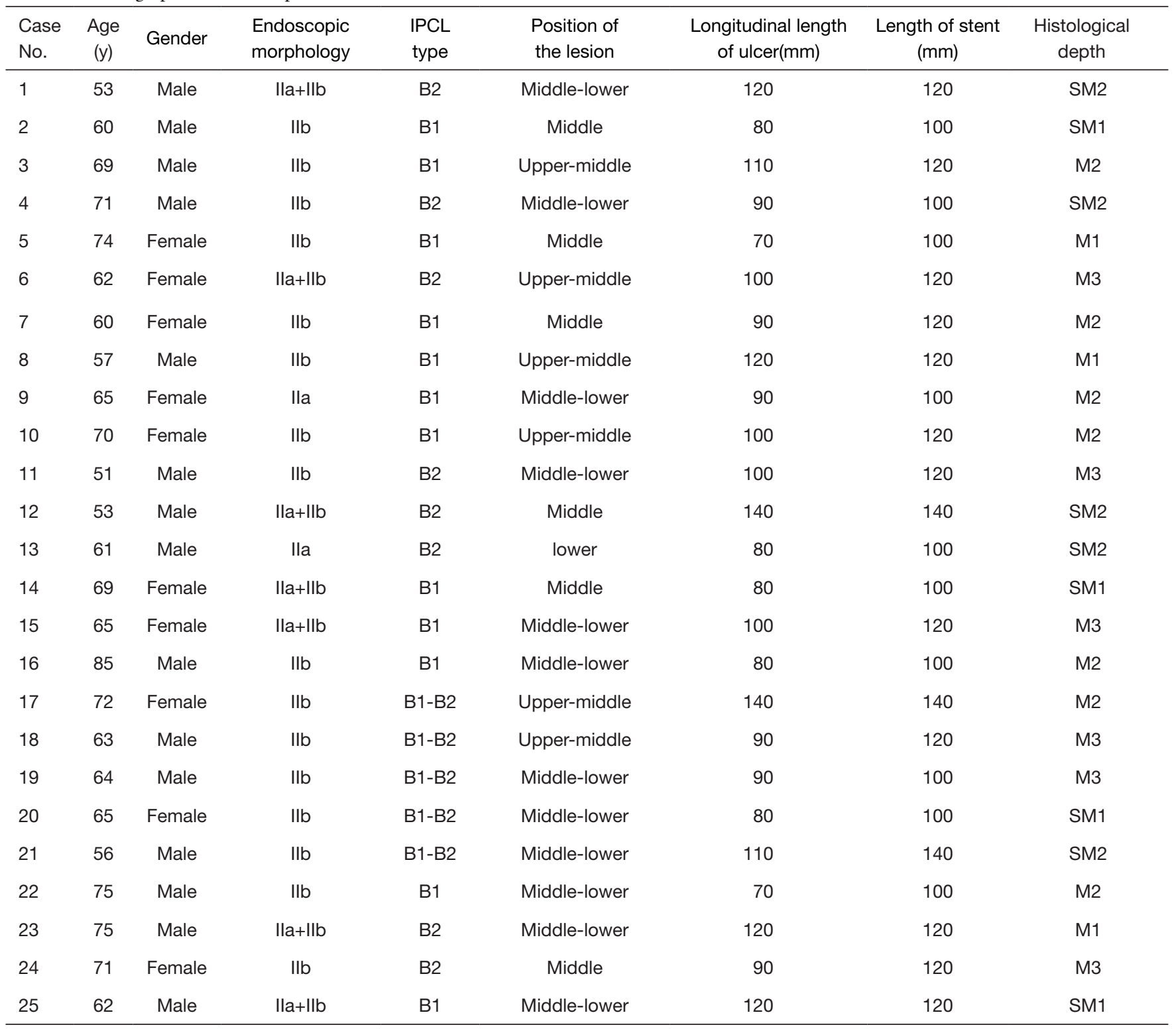

IPCL, Intraepithelial papillary capillary loops.

PGA sheet and absorbable line were absorbed partly which were enough to let the mucosa separate from the stent. So when we remove the stent, there were no difficulties. Stent migration occurred in 2 patients. The stents fell into the stomach. We pulled them back to esophagus and adjusted the position of the stent during the follow-up endoscopy. One of the 2 patients experienced the stent migration twice so we remove his stent on the $5^{\text {th }}$ week when the stent migration happened the second time. No other complications, including bleeding, wound infections, or perforations, occurred. The demographic characteristics and lesion features of 25 patients are exhibited (Table 1). $E n$ bloc resection was achieved in each lesion. Regarding the tumor invasion depth and pathology, 3 intramucosal invasive carcinomas were limited to the epithelial layer, 7 intramucosal invasive carcinomas were limited to the lamina propria mucosa membrane, 6 intramucosal invasive carcinomas were limited to the muscularis mucosa membrane, and 9 invasive carcinomas were limited to the submucosa. The average ulcer longitudinal length was 98.00 
Table 2 Clinical outcomes of autologous esophageal mucosa with polyglycolic acid transplantation and temporary stent implantation

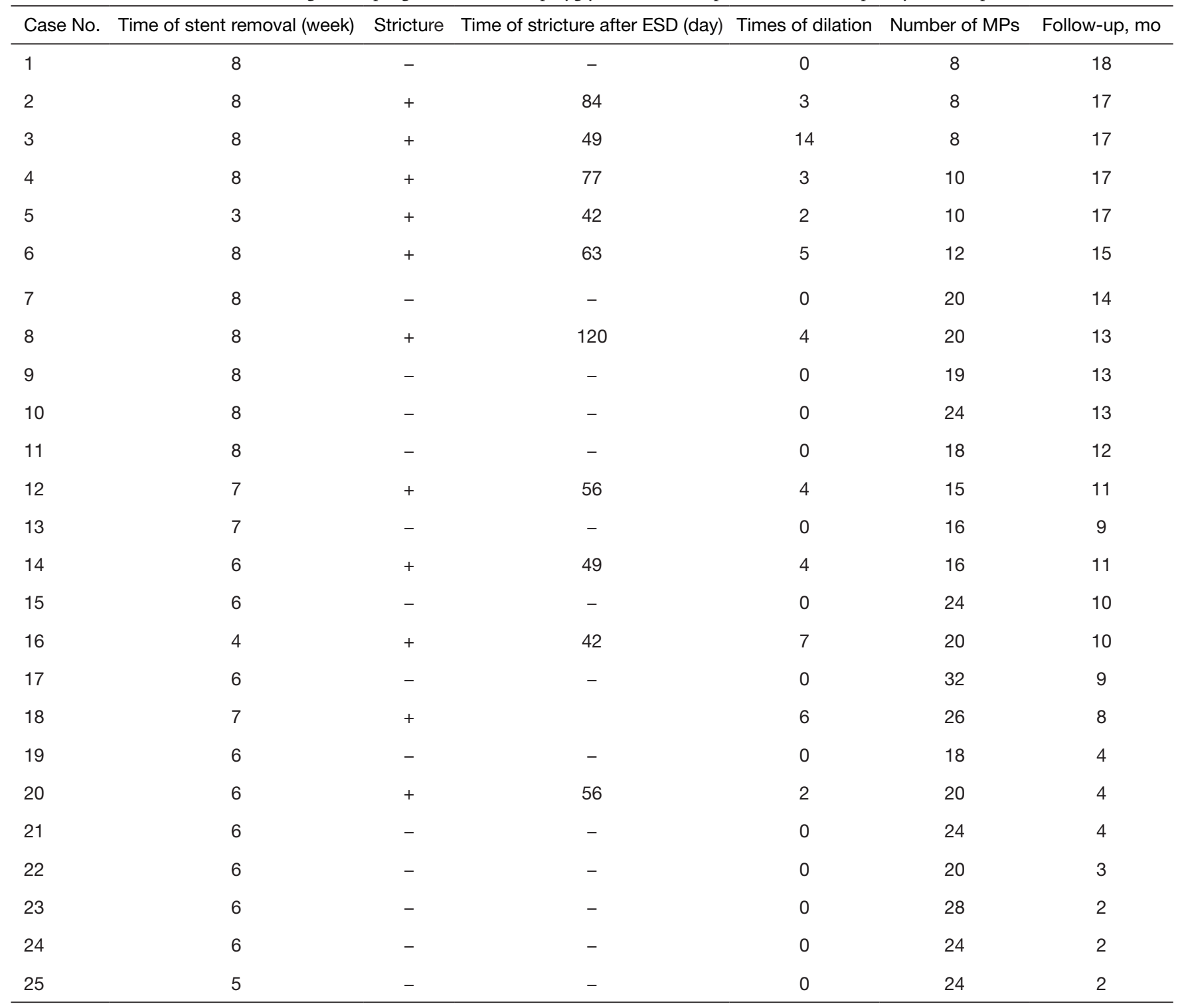

ESD, endoscopic submucosal dissection; MPs, mucosal patches.

$\mathrm{mm}$. On basis of the mucosal defect size and the normal esophagus length, the number of MPs varies between 8 and 32. The clinical results of the new operations are exhibited (Table 2). In total, 14 patients had no stenosis during an average follow-up of 10.2 months, and 11 patients suffered strictures at a mean interval of 63.73 days after the course. EBDs average was 2.16. One of the 11 patients suffered stricture before stent removal. The stenosis occurred in the anal side of the ulcer where had severe tissue proliferation. We advised all the cases of SM invasion to ask the radiotherapy doctor and thoracic surgeon for advice. One of the patients underwent additional surgery 9 months after ESD and he did not suffer from stricture before the surgery. Besides, 1 case of SM invasion underwent radiotherapy 4 months after ESD, and he had no stenosis.

\section{Comparison of groups with or without stricture}

The features of the patients with or without stricture are exhibited (Table 3). No significant difference existed in age, gender, longitudinal length of ulceration or length of stent between the two groups, while the patients without stricture 
Table 3 Characteristics and clinical results of patients with or without stricture

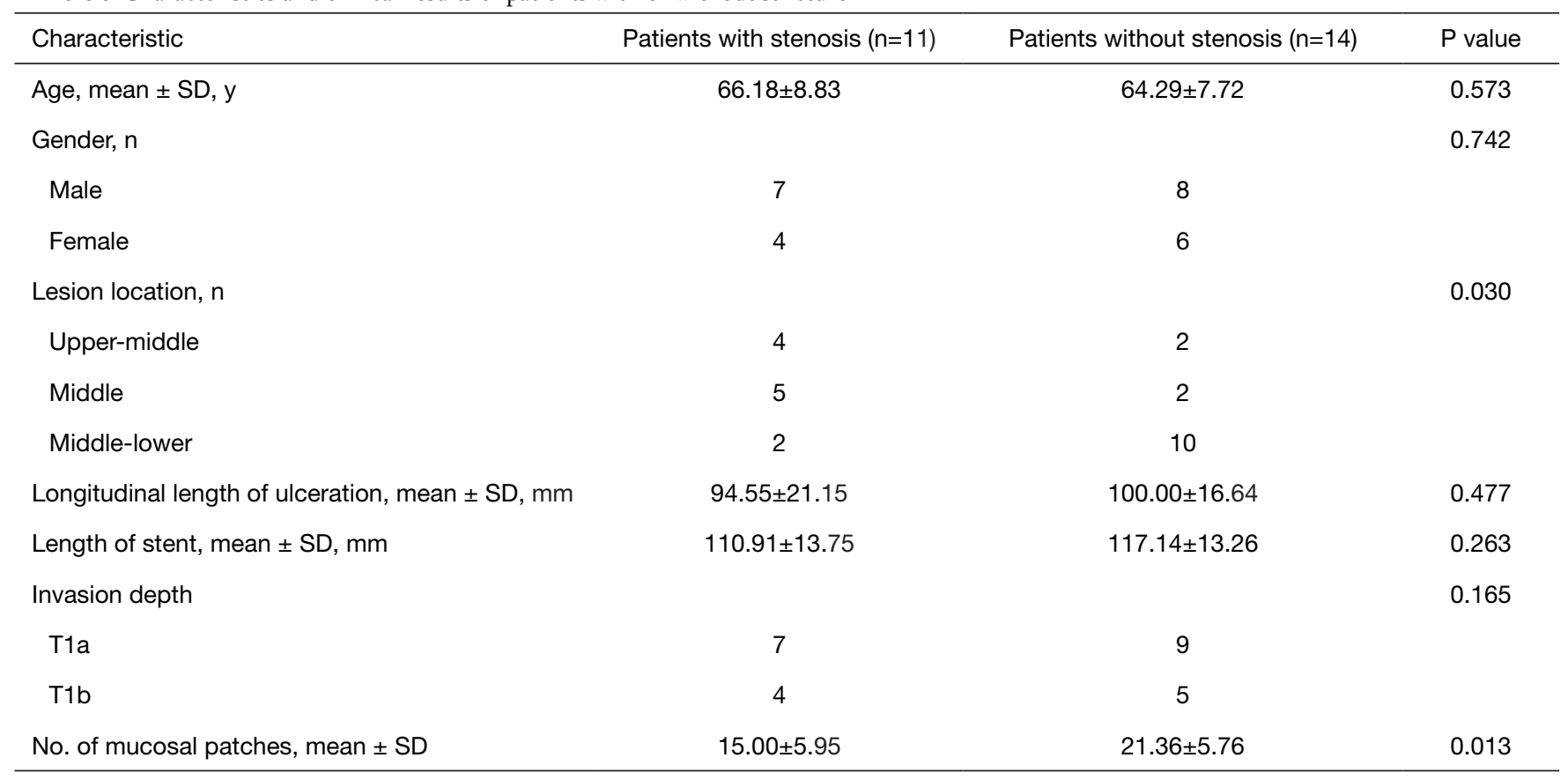

had more transplanted MPs $(\mathrm{P}<0.05)$, and the patients with lesions located in the middle-lower esophagus had a lower chance of developing post-ESD stricture $(\mathrm{P}<0.05)$.

\section{Discussion}

ES incidence after resecting wholly circumferential lesions varies between $88 \%$ and $100 \%(1,2)$. In the past few years, multiple approaches have been designed to prevent postoperative strictures. Sato et al. reported an average of 33.5 dilatations in patients after circumferential esophageal ESD and 13.8 dilatations in patients after circumferential esophageal ESD with the administration of after-dilatation steroids (15). In our hospital, the mean incidence of strictures and EBD number in patients after circumferential esophageal ESD with no specific treatment were $98.21 \%$ and $10.16 \%$, respectively. More EBD operations result in heavier economic burdens to patients. The outcomes demonstrate that autologous esophageal mucosal transplantation can not only clearly lessen the incidence of stenosis but also remarkably reduce the mean time of the EBD operation.

As for the method to choose the suitable length of stent, many researchers suggest that that approximately $2 \mathrm{~cm}$ of the stent extended beyond both the top and bottom borders of the mucosal defect to reduce stent migration (9). But longer stent will cause more serious thoracalgia to the patient, especially the patients whose proximal border of ulcer within $22 \mathrm{~cm}$ to the incisors. In our study, we found that the stent can be effective as long as the stent can cover the ulcer. On the other hand, if the ulcer was within $10 \mathrm{~cm}$ and the distance of proximal border from the incisors was longer than $22 \mathrm{~cm}$, we would prefer the stent longer than the ulcer to reduce stent migration.

Many researchers have focused on steroid therapy to decrease stricture. Two observational investigations reported the efficacy of systemic (oral) steroids in decreasing the incidence of post-ESD stenosis $(16,17)$. A systematic review identified that high-dose steroids can result in gastrointestinal ulcer, osteoporosis, immunosuppression, hyperglycemia, and even systemic infection (18). A systematic review exhibited a steroid injection was better than systemic (oral) steroids (19). Nevertheless, in some patients, intractable stenosis still occurs after local injection of steroids. Hanaoka et al. (20) and Nagami et al. (21) reported that even after a prophylactic steroid injection, $>3 / 4$ or $>5 / 6$ circumferential mucosal defect were independent risk factors for refractory strictures even after prophylactic steroid injections. Therefore, many studies reported different methods to prevent the post-ESD strictures of circumferential mucosal defect.

In 2015, Sakaguchi et al. reported that PGA sheets reduced stenosis incidence in $37.5 \%$ of patients with mucosal defects 
of over 3/4 of the esophageal circumference (22). However, a limitation of this method is that the PGA is easy to shift, and whether PGA is useful for patients after wholly circumferential esophageal ESD is unclear. Ohki et al. transplanted tissueengineered autologous oral mucosal epithelial cell sheets by endoscopy (11). However, it is still technically difficult and costly to transplant tissue-engineered autologous oral mucosal epithelial cell sheets. Additionally, the only wholly circumferential patient in his study experienced structure and 21 dilations. Recently, some researchers have reported that the autologous gastric mucosa (23) or skin (12) transplantation could prevent strictures. However, gastric antral mucosa, which can secrete gastric acid, may result in undesired symptoms, such as chest pain or even observable ulcerations. Theoretically, skin tissues may be unfavorable because of sweat secretion. Liao et al. reported that autologous esophageal mucosal transplantation can lessen the mean number of dilatation sessions needed (13). A research study by Chai et al. published in 2018 showed PGA sheets plus esophageal stent placement could lessen ES occurrence in patients with a circumferential lesion range to $42.86 \%$ (6/14) (24). However, the number of patients with circumferential lesions in that study was only 14 , and the follow-up period was only 3 months. Actually, we applied PGA sheets plus esophageal stent placement in 3 patients with complete circular ESD with no remaining normal mucosa to transplant. Severe strictures occurred in these 3 patients.

In our study, we creatively combined temporary stent insertion, AEM and PGA transplantation to prevent strictures of circumferential mucosal defect. Furthermore, in this study, we found that more esophageal mucosal patch transplantation lowers the risk of post-ESD strictures for circumferential lesions. Besides, circumferential lesions situated in the upper-middle esophagus have a higher risk of post-ESD strictures.

For the circumferential lesions situated in the uppermiddle esophagus, there are few researches just focused on the upper-middle esophagus stenosis. The researches of EBD, oral steroids, local injection of steroids, oral mucosal sheets, autologous skin grafting and AEM (1,5,6,9-13) all include the cases of upper-middle esophagus. So comprehensive approaches should be considered for the circumferential lesions situated in the upper-middle esophagus. In our study, these cases were treated by EBD when they had strictures after stent removal.

Some restrictions still exist in our investigation. For starters, this investigation was a small sample single-center research. Secondly, this investigation was a single-arm research, and hence, selection bias is possible because we designed this study as a phase I study. In the near future, we aim to conduct a prospective, multicenter, single-arm phase II study. Third, as few patients undergo complete circular ESD, we did not establish a control group in which a stent alone or a stent plus a PGA sheet were employed for preventing post-ESD stenosis. However, as far as we know, this study is the first report on preventing ES after ESD by AEM combined with PGA transplantation and TSI.

In conclusion, our preliminary research shows that the operation of an AEM with PGA transplantation and TSI is feasible and effective in reducing strictures and promoting the life quality after circumferential ESD.

\section{Conclusions}

AEM with PGA transplantation and TSI is a safe and effective approach of preventing esophageal stricture and improving the quality of life after circumferential ESD.

\section{Acknowledgments}

Funding: This research was supported by grants from (I) the National Key Research and Development Program of China (grant No. 2016YFC1302800, 2018YFC1313100); (II) Shenzhen Sanming Medical Project (No. SZSM201911008); (III) CAMS Innovation Fund for Medical Sciences (CIFMS); (approval No. 2016-I2M-1-001, 2017-I2M1-001, 2019-I2M-2-004); (IV) the PUMC Youth Fund and the Fundamental Research Funds for the Central Universities (approval No. 2017320012); (V) Capital Health Improvement and Research Fund (grant No. 2020-2-4025); and (VI) PUMC Graduate Innovation Fund (approval No. 2019-1002-81).

\section{Footnote}

Reporting Checklist: The authors have completed the STROBE reporting checklist. Available at http://dx.doi. org/10.21037/atm-20-6987

Data Sharing Statement: Available at http://dx.doi. org/10.21037/atm-20-6987

Peer Review File: Available at http://dx.doi.org/10.21037/ atm-20-6987

Conflicts of Interest: All authors have completed the ICMJE 
uniform disclosure form (available at http://dx.doi. org/10.21037/atm-20-6987). The authors have no conflicts of interest to declare.

Ethical Statement: The authors are accountable for all aspects of the work in ensuring that questions related to the accuracy or integrity of any part of the work are appropriately investigated and resolved. The study was conducted in accordance with the Declaration of Helsinki (as revised in 2013). The study was approved by the Ethics Committee of the National Cancer Center/Cancer Hospital, Chinese Medical College and Peking Union Medical College (No. 19/191-1975), and informed consent was taken from all individual participants.

Open Access Statement: This is an Open Access article distributed in accordance with the Creative Commons Attribution-NonCommercial-NoDerivs 4.0 International License (CC BY-NC-ND 4.0), which permits the noncommercial replication and distribution of the article with the strict proviso that no changes or edits are made and the original work is properly cited (including links to both the formal publication through the relevant DOI and the license). See: https://creativecommons.org/licenses/by-nc-nd/4.0/.

\section{References}

1. Ishihara R. Prevention of esophageal stricture after endoscopic resection. Dig Endosc 2019;31:134-45.

2. Chen M, Dang Y, Ding C, et al. Lesion size and circumferential range identified as independent risk factors for esophageal stricture after endoscopic submucosal dissection. Surg Endosc 2020;34:4065-71.

3. Yu JP, Liu Y, Tao Y, et al. Prevention of Esophageal Stricture After Endoscopic Submucosal Dissection: A Systematic Review. World J Surg 2015;39:2955-64.

4. Shi P, Ding X. Progress on the Prevention of Esophageal Stricture after Endoscopic Submucosal Dissection. Gastroenterol Res Pract 2018;2018:1696849.

5. Qiu Y, Shi R. Roles of Steroids in Preventing Esophageal Stricture after Endoscopic Resection. Can J Gastroenterol Hepatol 2019;2019:5380815.

6. Iizuka T, Kikuchi D, Hoteya S, et al. Effectiveness of modified oral steroid administration for preventing esophageal stricture after entire circumferential endoscopic submucosal dissection. Dis Esophagus 2018;31:1-6.

7. Bahin FF, Jayanna M, Williams SJ, et al. Efficacy of viscous budesonide slurry for prevention of esophageal stricture formation after complete endoscopic mucosal resection of short-segment Barrett's neoplasia. Endoscopy 2016;48:71-4.

8. Nagami Y, Shiba M, Tominaga K, et al. Hybrid therapy with locoregional steroid injection and polyglycolic acid sheets to prevent stricture after esophageal endoscopic submucosal dissection. Endosc Int Open 2016;4:E1017-22.

9. Ye LP, Zheng HH, Mao XL, et al. Complete circular endoscopic resection using submucosal tunnel technique combined with esophageal stent placement for circumferential superficial esophageal lesions. Surg Endosc 2016;30:1078-85.

10. Iizuka T, Kikuchi D, Yamada A, et al. Polyglycolic acid sheet application to prevent esophageal stricture after endoscopic submucosal dissection for esophageal squamous cell carcinoma. Endoscopy 2015;47:341.

11. Ohki T, Yamato M, Ota M, et al. Prevention of Esophageal Stricture After Endoscopic Submucosal Dissection Using Tissue-Engineered Cell Sheets. Gastroenterology 2012;143:582-8.e2.

12. Chai N, Zou J, Linghu E, et al. Autologous Skin-Grafting Surgery to Prevent Esophageal Stenosis After Complete Circular Endoscopic Submucosal Tunnel Dissection for Superficial Esophageal Neoplasms. Am J Gastroenterol 2019;114:822-5.

13. Liao Z, Liao G, Yang X, et al. Transplantation of autologous esophageal mucosa to prevent stricture after circumferential endoscopic submucosal dissection of early esophageal cancer (with video). Gastrointest Endosc 2018;88:543-6.

14. Liu Y, Li Z, Dou L, et al. Autologous esophageal mucosa with polyglycolic acid transplantation and temporary stent implantation for the prevention of esophageal stenosis after circumferential endoscopic submucosal dissection. VideoGIE 2020;5:230-2.

15. Sato H, Inoue H, Kobayashi Y, et al. Control of severe strictures after circumferential endoscopic submucosal dissection for esophageal carcinoma: oral steroid therapy with balloon dilation or balloon dilation alone. Gastrointest Endosc 2013;78:250-7.

16. Kataoka M, Anzai S, Shirasaki T, et al. Efficacy of short period, low dose oral prednisolone for the prevention of stricture after circumferential endoscopic submucosal dissection (ESD) for esophageal cancer. Endosc Int Open 2015;3:E113-7.

17. Zhou G, Yuan F, Cai J, et al. Efficacy of prednisone for prevention of esophageal stricture after endoscopic 


\section{Page 10 of 10}

submucosal dissection for superficial esophageal squamous cell carcinoma. Thorac Cancer 2017;8:489-94.

18. Oliveira JF, Moura EGH, Bernardo WM, et al. Prevention of esophageal stricture after endoscopic submucosal dissection: a systematic review and meta-analysis. Surg Endosc 2016;30:2779-91.

19. Wang W, Ma Z. Steroid Administration is Effective to Prevent Strictures After Endoscopic Esophageal Submucosal Dissection. Medicine 2015;94:e1664.

20. Hanaoka N, Ishihara R, Uedo N, et al. Refractory strictures despite steroid injection after esophageal endoscopic resection. Endosc Int Open 2016;4:E354-9.

21. Nagami Y, Ominami M, Shiba $M$, et al. Prediction of esophageal stricture in patients given locoregional triamcinolone injections immediately after endoscopic submucosal dissection. Dig Endosc

Cite this article as: Liu Y, Li Z, Dou L, Zhang Y, He S, Zhu J, Ke Y, Liu X, Liu Y, Ng H, Wang G. Autologous esophageal mucosa with polyglycolic acid transplantation and temporary stent implantation can prevent stenosis after circumferential endoscopic submucosal dissection. Ann Transl Med 2021;9(7):546. doi: 10.21037/atm-20-6987

\section{Liu et al. AEM with PAG and TSI to prevent stenosis after cESD}

2018;30:198-205.

22. Sakaguchi Y, Tsuji Y, Ono S, et al. Polyglycolic acid sheets with fibrin glue can prevent esophageal stricture after endoscopic submucosal dissection. Endoscopy 2015;47:336.

23. Hochberger J, Koehler P, Wedi E, et al. Transplantation of Mucosa From Stomach to Esophagus to Prevent Stricture After Circumferential Endoscopic Submucosal Dissection of Early Squamous Cell. Gastroenterology 2014;146:906-9.

24. Chai NL, Feng J, Li LS, et al. Effect of polyglycolic acid sheet plus esophageal stent placement in preventing esophageal stricture after endoscopic submucosal dissection in patients with early-stage esophageal cancer: A randomized, controlled trial. World J Gastroenterol 2018;24:1046-55. 